\title{
Skor Prediktor Kematian Sepsis Neonatorum Awitan Dini
}

\author{
Riski Kawa Ramadani, Alifah Anggraini, Setya Wandita \\ Departemen Ilmu Kesehatan Anak Fakultas Kedokteran Universitas Gadjah Mada, Yogyakarta
}

\begin{abstract}
Latar belakang. Sepsis neonatorum awitan dini memiliki angka kematian tinggi dan sering memerlukan perawatan intensif. Beberapa sistem skor dikembangkan sebagai prediktor luaran, tetapi sering hanya pada berat lahir rendah atau memerlukan banyak pemeriksaan penunjang. Sistem skoring baru yang mudah, sederhana, cepat, dan dapat diaplikasikan akan memudahkan klinisi memprediksi luaran untuk pemilihan intervensi maupun konseling.

Tujuan. Mengembangkan model skor sebagai prediktor kematian sepsis neonatorum awitan dini.

Metode. Penelitian kohort retrospektif di RSUP Dr. Sardjito Yogyakarta menggunakan data sekunder bayi lahir bulan Januari 2014 - Mei 2015 dengan sepsis neonatorum awitan dini sesuai kriteria klinis. Bayi dieksklusi jika memiliki kelainan bawaan mayor atau data tidak lengkap. Pengembangan sistem skoring dengan metode Spiegelhalter Knill-Jones. Pembobotan skor digunakan nilai koefisien regresi logistik, sedangkan penentuan nilai titik potong skor digunakan kurva receiver operating characteristics (ROC).

Hasil. Seratus delapan subjek memenuhi kriteria inklusi dan eksklusi. Mortalitas sebesar 24\%. Pengambilan skor 6 variabel yang memenuhi nilai LR, yaitu usia kehamilan ( $\leq 33$ minggu: skor: $2,>33$ minggu: skor -4$)$, asfiksia (ya: 4 , tidak: -5$)$, leukopenia $(\leq 5000$ : 10, >5000: 0), Trombositopenia ( $\leq 100.000: 5,>100.000: 0)$, absolute neutrophyl count ( $\leq 2000: 18$, $>2000:-1)$, dan biakan kuman (tumbuh: 10, tidak tumbuh: -3). Area under curve (AUC) adalah 83,8\% (74,3\%-92\%). Titik potong pada skor 2 memiliki sensitivitas $84,6 \%$, spesifisitas $64,4 \%$, nilai ramal positif $43 \%$, nilai ramal negatif $93 \%$, likelihood ratio (LR) positif 2,39, dan LR negatif 0,24 .

Kesimpulan. Skor $\geq 2$ dapat memprediksi kematian sepsis neonatorum awitan dini. Sari Pediatrï 2016;18(2):117-21
\end{abstract}

Kata kunci: sepsis neonatorum, awitan dini, skor, prediksi, kematian

\section{Mortality Prediction Score of Early-Onset Neonatal Sepsis}

Riski Kawa Ramadani, Alifah Anggraini, Setya Wandita

Background. Early-onset neonatal sepsis have higher mortality rate often and needs intensive care support. Several prediction systems have been established, but some of those developed only for low birth weight or for requirement lot of examinations parameters. We develop new scoring system which is simple, and applicable not only in tertiary hospital.

Objective. To establish prediction score for mortality of early-onset neonatal sepsis.

Method. A cohort study that was conducted from data of newborn babies with clinical early-onset neonatal sepsis born at RSUP Dr. Sardjito Hospital, Yogyakarta from January 2014 till May 2015. We excluded samples with major congenital defect and/or insufficient data. We defined the score based on Spiegelhalter-Knill-Jones method. Weighing up score adjustment is use logistic regression, cut-off point determination was based upone receiver operating characteristic (ROC) curve.

Result. 108 samples are fulfilled our inclusion and exclusion criteria. Mortality of early-onset neonatal sepsis was $24 \%$. Score is composed of 6 variables that fulfill criteria, which were: gestational of ages ( $\leq 33$ weeks: $2,>33$ weeks: -4$)$, asphyxia (yes: 4 , no: -5 ), leukopenia ( $\leq 5000: 10,>5000: 0)$, thrombocytopenia ( $\leq 100.000: 5,>100.000: 0)$, absolute neutrophil count $(\leq 2000: 18,>2000$ : -1 ), and blood culture (positive: 10 , negative: -3 ). Cut off at score $\geq 2$ has sensitivity $84,6 \%$, specificity $64,4 \%$, positive predictive value 43\%, negative predictive value 93\%, positive likelihood ratio (LR): 2,39, and negative LR: 0,24.

Conclusion. Score $\geq 2$ can be used to predict mortality of early-onset neonatal sepsis. Sari Pediatri 2016;18(2):117-21

Keyword: neonatal sepsis, early-onset, score, prediction, mortality

\footnotetext{
Alamat korespondensi: Dr. Riski Kawa Ramadani. Departemen Ilmu Kesehatan Anak Fakultas Kedokteran Universitas Gadjah Mada, Yogyakarta. E-mail: riskikawa@gmail.com
} 
S epsis neonatorum masih merupakan penyebab utama mobiditas dan mortalitas di negara berkembang. ${ }^{1}$ Berdasarkan 32 penelitian di negara berkembang, kematian karena infeksi berkisar 8\%-80\% (median 36,5\%). ${ }^{2} \mathrm{Di}$ antara seluruh penyebab kematian neonatus dalam minggu pertama, $42 \%$ kematian terjadi karena infeksi. ${ }^{2}$ Sepsis neonatorum awitan dini biasanya memburuk dengan cepat, cenderung mengakibatkan keterlibatan multiorgan, dan juga memiliki kematian lebih tinggi dibandingkan dengan sepsis awitan lambat. ${ }^{3}$

Imaturitas sistem imun pada neonatus meningkatkan kemungkinan terjadinya infeksi berat dengan peluang kematian tinggi. ${ }^{4,5}$ Mengidentifikasi profil klinis pada neonatus berisiko akan membantu klinisi mengidentifikasi neonatus mana yang membutuhkan monitoring ketat dan perawatan kritis sehingga dapat segera dilakukan terapi agresif. ${ }^{5}$ Menetapkan profil risiko klinis juga membantu tim medis mengembangkan strategi untuk mencegah luaran buruk. ${ }^{5}$

Hubungan antara berat lahir rendah dan prematuritas sebagai faktor prediktor telah digambarkan pada penelitian sebelumnya. ${ }^{6-10}$ Semakin kurang bulan, neonatus rentan mengalami komplikasi sepsis karena defisiensi imunitas humoral dan selular. Meski antibodi maternal transplasenta dapat memediasi imunitas humoral, neonatus kurang bulan sangat sedikit menerima imunoglobulin dari ibu dibanding bayi cukup bulan. ${ }^{5}$ Disamping itu, Fungsi sel $\mathrm{T}$ dan fagoistosis bayi berat lahir rendah dan kurang bulan mengalami defisiensi. ${ }^{5}$

Parameter hematologis juga dapat digunakan untuk memprediksi luaran sepsis neonatorum, ${ }^{11-13}$ antara lain, anemia, leukopenia, trombositopenia, dan juga nilai neutrofil absolut rendah. ${ }^{14}$ Tujuan penelitian ini adalah untuk menyusun skor prediktor kematian sepsis neonatorum awitan dini.

\section{Metode}

Dilakukan penelitian kohort retrospektif dengan data sekunder dari instalasi maternal perinatal (IMP) RSUP Dr. Sardjito Yogyakarta dari bulan Januari 2014 hingga Mei 2015. Subjek penelitian adalah bayi yang dilahirkan di RSUP Dr. Sardjito dengan sepsis neonatorum awitan dini ( $<72$ jam) sesuai kriteria klinis. Kriteria eksklusi adalah bayi yang lahir dengan kelainan bawaan mayor atau data laboratorium tidak lengkap pada waktu $<72$ jam.
Besar sampel dihitung menggunakan uji dua sampel proporsi dengan luaran likelihood ratio (LR) atau Odds ratio (OR). Pengambilan sampel dilakukan secara consecutive sampling. Kami mengambil data karakteristik awal yaitu jenis kelamin, usia kehamilan, berat lahir, cara lahir, dan kejadian asfiksia, serta parameter laboratorium dasar yang diperiksa $<72$ jam.

Sistem skoring dikembangkan dengan metode Spiegelhalter Knill-Jones. Prediktor kematian yang memiliki LR positif $(+) \geq 2$ dan negatif $(-) \leq 0,5$ dimasukkan dalam penghitungan skor. Nilai LR dikonversikan menjadi sistem skor dengan menggunakan natural logarithm. Kemudian dilakukan pembobotan skor awal (crude weight) menjadi skor akhir (adjusted weight) dengan perhitungan nilai koefisien variabel melalui analisis regresi logistik. Dengan menjumlahkan skor dari semua faktor prediksi kematian pada pasien didapatkan skor total kematian. Untuk menentukan nilai titik potong skor, digunakan kurva receiver operating characteristics (ROC). Digunakan program SPSS for Windows version 16.0 untuk analisis data.

\section{Hasil}

\section{Karakteristik pasien}

Terdapat 199 neonatus dengan diagnosis sepsis sesuai kriteria klinis dengan data hematologis lengkap dari bulan Januari 2014 hingga Mei 2015. Setelah dilakukan eksklusi, tersisa 108 subjek penelitian. Data karakteristik dasar pada penelitian ini tertera pada Tabel 2.

Mortalitas sepsis neonatorum awitan dini adalah 24\%. subjek laki-laki 46\% meninggal, sedangkan perempuan (54\%). Usia kehamilan 28-34 minggu adalah kelompok terbanyak mengalami kematian (54\%), disusul <28 minggu (23\%). Kematian sering terjadi pada BBLSR dan BBLER (39\%). Kematian berdasarkan cara lahir sectio caesarea maupun pervaginam memiliki angka kematian seimbang $(50 \%)$. Bayi yang menderita asfiksia mayoritas meninggal $(77 \%)$.

\section{Prediktor kematian pada sepsis neonatorum awitan dini}

Berdasarkan penelitian sebelumnya, usia kehamilan $<33$ minggu, ${ }^{5}$ berat lahir $<2000$ gram $^{14}$ atau 1500 gram, ${ }^{5}$ menderita asfiksia, ${ }^{14}$ leukopenia $<5000$ 
Tabel 1. Karakteristik dasar subyek penelitian

\begin{tabular}{lccc}
\hline Karakteristik & $\begin{array}{c}\text { Meninggal } \\
\mathrm{n}=48\end{array}$ & $\begin{array}{c}\text { Hidup } \\
\mathrm{n}=75\end{array}$ & $\begin{array}{c}\text { Total } \\
\mathrm{n}=108\end{array}$ \\
$\begin{array}{l}\text { Jenis kelamin, n (\%) } \\
\quad \text { Laki-laki }\end{array}$ & $12(46)$ & $46(77)$ & $60(56)$ \\
$\quad$ Perempuan & $14(54)$ & $36(44)$ & $48(44)$ \\
Usia kehamilan, & & & \\
minggu, n (\%) & & & \\
$\quad<28$ & $6(23)$ & $3(4)$ & $9(9)$ \\
$\quad 28-34$ & $14(54)$ & $42(51)$ & $56(52)$ \\
$34-36$ & $2(8)$ & $19(23)$ & $21(19)$ \\
$\quad \geq 37$ & $4(15)$ & $18(22)$ & $22(20)$ \\
Berat lahir, n (\%) & & & \\
$\quad$ BBLER & $10(39)$ & $2(2)$ & $12(11)$ \\
$\quad$ BBLSR & $10(39)$ & $31(38)$ & $41(38)$ \\
$\quad$ BBLR & $2(7)$ & $32(39)$ & $34(31)$ \\
$\quad$ BBLC & $3(11)$ & $15(18)$ & $18(17)$ \\
$\quad$ BBLB & $1(4)$ & $2(2)$ & $3(3)$ \\
Cara lahir, n (\%) & & & \\
$\quad$ Sectio caesarea & $13(50)$ & $34(58)$ & $61(57)$ \\
$\quad$ Pervaginam & $13(50)$ & $48(42)$ & $47(43)$ \\
Kejadian asfiksia, n (\%) & & & \\
$\quad$ Ada & $19(73)$ & $35(43)$ & $54(50)$ \\
$\quad$ Tidak & $7(27)$ & $47(57)$ & $54(50)$ \\
\hline
\end{tabular}

$\mathrm{sel} / \mathrm{mm}^{3},{ }^{14}$ trombositopenia $<150.000 \mathrm{sel} / \mathrm{mm}^{3},{ }^{5}$ atau $<100.000 \mathrm{sel} / \mathrm{mm}^{3},{ }^{14}$ biakan kuman tumbuh, dan absolute neutrophyl count (ANC) <2000 sel/ $\mathrm{mm}^{3},{ }^{14}$ merupakan prediktor kematian pada sepsis neonatorum. Dari hasil analisis, variabel yang memiliki LR (+) sebesar $\geq 2$ atau LR $(-) \leq 0,5$ adalah usia kehamilan $<33$ minggu, menderita asfiksia, leukopenia $<5000 \mathrm{sel} / \mathrm{mm}^{3}$, trombositopenia $<100.000 \mathrm{sel} / \mathrm{mm}^{3}$, ANC $\leq 2000 \mathrm{sel} / \mathrm{mm}^{3}$, dan biakan kuman tumbuh, berat lahir $<1500$ gram dieksklusi karena berinteraksi secara biologis dengan usia kehamilan. Kemudian disusun skor berdasarkan 6 variabel tersebut dengan total skor keseluruhan adalah 26, skor terendah -18 dan tertinggi 44 (Tabel 2).

Dari Gambar 1, tampak kurva ROC dengan AUC (area under curve) 83,2\% dengan interval konfidens 74,3\%-92\%. Titik potong pada skor 1 , memiliki sensitivitas $84,6 \%$, spesifisitas $62,2 \%$, nilai ramal positif 42\%, nilai ramal negatif 93\%, LR (+) 2,24, dan LR (-) 0,25. Sementara titik potong pada skor 2 , memiliki sensitivitas $84,6 \%$, spesifisitas $64,4 \%$, nilai ramal positif $43 \%$, nilai ramal negatif $93 \%$, LR (+) 2,39, dan LR (-) 0,24. Disisi lain, titik potong 3

Tabel 2. Skor prediktor kematian pada sepsis neonatorum awitan dini

\begin{tabular}{|c|c|c|c|c|c|}
\hline Karakteristik & $\begin{array}{c}\text { Meninggal } \\
\mathrm{n}=26\end{array}$ & $\begin{array}{l}\text { Hidup } \\
\mathrm{n}=82\end{array}$ & $\begin{array}{l}\mathrm{LR}(+) \geq 2 \\
\operatorname{LR}(-)<2\end{array}$ & $\begin{array}{l}\text { Crude } \\
\text { weight }\end{array}$ & $\begin{array}{c}\text { Adjusted } \\
\text { weight }\end{array}$ \\
\hline \multicolumn{6}{|l|}{ Usia (minggu) } \\
\hline$\leq 33$ & 21 & 45 & 1,47 & 2,3 & 8 \\
\hline$>33$ & 5 & 37 & 0,43 & $-3,3$ & 0 \\
\hline \multicolumn{6}{|l|}{ Asfiksia } \\
\hline Ya & 19 & 35 & 1,71 & 1,7 & 4 \\
\hline Tidak & 7 & 47 & 0,47 & $-3,7$ & -7 \\
\hline \multicolumn{6}{|c|}{ Leukopenia (sel/mm³) } \\
\hline$\leq 5000$ & 2 & 1 & 6,31 & 8,0 & 4 \\
\hline$>5000$ & 24 & 81 & 0,93 & $-0,3$ & 0 \\
\hline \multicolumn{6}{|c|}{ Trombositopenia (sel/mm³) } \\
\hline$\leq 100.000$ & 3 & 4 & 2,56 & 3,7 & 6 \\
\hline$>100.000$ & 23 & 78 & 0,91 & $-0,3$ & -1 \\
\hline \multicolumn{6}{|l|}{$\mathrm{ANC}^{*}\left(\mathrm{sel} / \mathrm{mm}^{3}\right)$} \\
\hline$\leq 2000$ & 4 & 2 & 2,04 & 8 & 15 \\
\hline$>2000$ & 22 & 80 & 0,64 & $-0,6$ & -1 \\
\hline \multicolumn{6}{|l|}{ Biakan kuman } \\
\hline Tumbuh & 10 & 8 & 3,94 & 6,0 & 12 \\
\hline Tidak tumbuh & 16 & 74 & 0,68 & $-1,7$ & -3 \\
\hline
\end{tabular}

* absolute neutrophyl count 


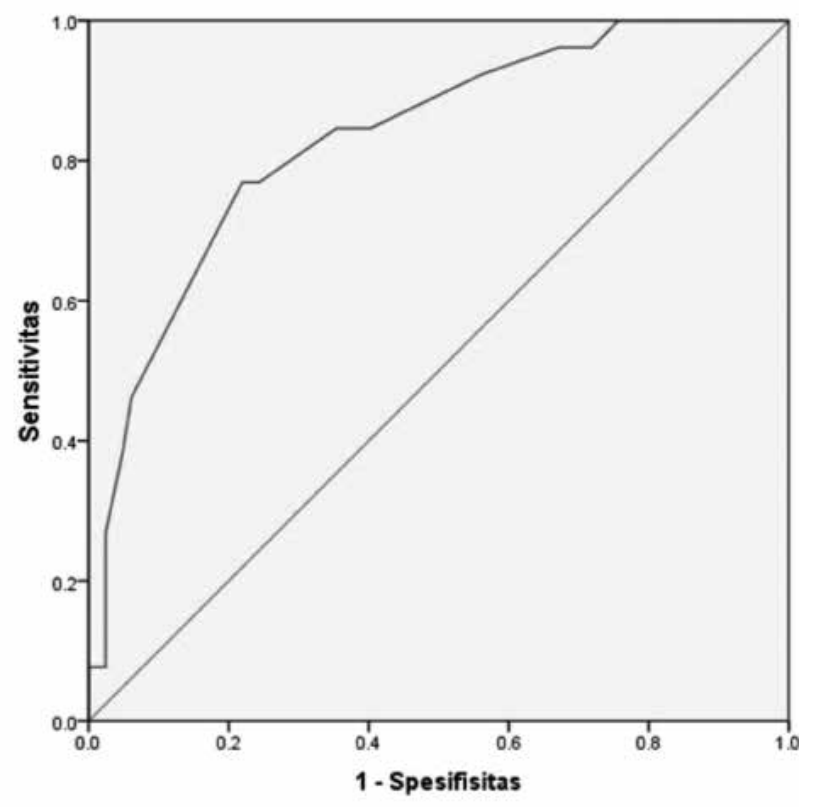

Gambar 1. Kurva ROC skor prediksi kematian pada sepsis neonatorum awitan dini

memiliki sensitivitas hanya sebesar $76,9 \%$, spesifisitas $75,6 \%$, nilai ramal positif $50 \%$, nilai ramal negatif 91\%, dan nilai LR (+) 3,15, serta LR (-) 0,31.

\section{Pembahasan}

Sepsis awitan dini banyak ditemui pada usia kehamilan kurang bulan dan berat badan lahir rendah, karakteristik ini sama dengan penelitian sebelumnya. ${ }^{11,16,17}$ Penelitian menggunakan parameter laboratorium sederhana sebagai prediktor kematian telah dilakukan, antara lain, leukopenia, rerata $\mathrm{Hb}$, dan trombositopenia, meski belum dilakukan analisis multivariat. ${ }^{5,17}$ Absolute neutrophyl count (ANC) dan trombositopenia juga pernah diteliti sebagai prediktor luaran kematian dengan analisis multivariat. ${ }^{14}$ Namun, belum ada sistem skoring yang menggabungkan beberapa parameter untuk memprediksi kematian neonatus khusus pada sepsis awitan dini. Pada penelitian kami, ANC $\leq 2000$ $\mathrm{sel} / \mathrm{mm}^{3}$ memiliki skor tertinggi dibanding parameter lain, yaitu 18 poin, diikuti biakan kuman tumbuh (10 poin), leukopenia (10 poin), dan trombositopenia $\leq 100.000 \mathrm{sel} / \mathrm{mm}^{3}$ sebesar 5 poin.

Sistem skoring untuk prediktor morbiditas dan atau mortalitas semakin luas digunakan. Sistem skoring dapat memberikan standarisasi penilaian. Penggunaan sistem skoring juga dapat memberikan informasi prognosis pada orang tua mengenai kondisi bayinya. ${ }^{18}$ Penerapan sistem skoring juga membantu menilai luaran spesifik untuk pembuatan case mix, atau hanya untuk mengidentifikasi bayi dengan risiko tinggi yang memerlukan intervensi tertentu. ${ }^{18}$ Sistem skoring yang sudah ada hampir seluruhnya memerlukan pemeriksaan yang menyeluruh, data berbagai hasil laboratorium. ${ }^{18-20}$ Pengembangan skor pada penelitian kami hanya membutuhkan 2 parameter biologis, yaitu usia kehamilan dan kejadian asfiksia. Data laboratorium dasar, yaitu leukosit, trombosit, dan ANC. Sistem skoring ini juga memerlukan hasil biakan kuman sehingga sistem skor ini paling cepat dinilai pada usia 48 jam. Namun, ketika itu biasanya dilakukan evaluasi pemberian terapi untuk sepsis awitan dini yang dialami neonatus. Dengan sensitivitas yang baik, alat ini dapat digunakan sebagai skrining kasus sepsis neonatorum awitan dini yang berat ketika mengevaluasi kondisi neonatus, dengan LR (+) 2, 39. Selain itu, nilai ramal negatif tinggi (92\%) dan LR (-) 0,24 pada alat prediksi ini berguna sebagai tambahan informasi klinis untuk mengevaluasi terapi atau bahkan memberhentikan pemberian antibiotik jika hasil skor $<2$. Dari penelitian kohort retrospektif tahun 2011, pemanjangan pemberian antibiotik pada neonatus kurang bulan yang sembuh dari sepsis dan enterokolitis nekrotikans dengan biakan kuman negatif pada hari ke-7, berhubungan dengan sepsis awitan lambat (OR 2,5). ${ }^{21-23}$

Kelemahan penelitian ini adalah besar sampel kurang dan desain penelitian retrospektif. Perlu penelitian lebih lanjut secara prospektif untuk memprediksi luaran sepsis neonatorum awitan dini dengan sensitivitas dan spesifisitas tinggi.

\section{Kesimpulan}

Skor dengan metode Spiegelhalter-Knill-Jones $\geq 2$ dapat digunakan untuk memprediksi kematian sepsis neonatorum awitan dini.

\section{Daftar pustaka}

1. World Health Organization. Essential newborn care: In a report of a technical working group WH0. Geneva. 1995.

2. Thaver D, Zaidi AK. Burden of neonatal infections 
in developing countries: a review of evidence from community based studies. Pediatr Infect Dis J 2009; 28:S3-9.

3. Purba MA, Haksari EL. Faktor prediktor mortalitas sepsis neonatorum awitan dini di RSUP Dr.Sardjito Yogyakarta. Yogyakarta: Universitas Gadjah Mada, 2011. Didapat dari: http://etd.repository.ugm.ac.id/index. php?mod=penelitian_detailorsub=PenelitianDetailsact=view \&typ=htmlobuku_id $=51917$.

4. Wilson CB. Immunologic basis for increased susceptibility of the neonate to infection. J Pediatr 1986;108:1-12.

5. Trotman H, Bell Y, Thame M, Nicholson AM, Barton M. Predictors of Poor Outcome in Neonates with Bacterial Sepsis Admitted to the University Hospital of the West Indies. West Indian Med J 2006;55:80.

6. Fanaroff AA, Korones SB, Wright LL, Verter J, Poland $\mathrm{RL}$, Bauer CR, dkk. Incidence, presenting features, risk factors and significance of late onset septicemia in very low birth weight infants. The National Institute of Child Health and Human Development Neonatal Research Network. Pediatr Infect Dis J 1998;17:593-8.

7. Bhutta ZA, Yusuf K. Neonatal sepsis in Karachi: factors determining outcome and mortality. J Trop Paediatr 1997;43:65-70.

8. Gladstone IM, Ehrenkranz RA, Edberg SC, Baltimore RS. A ten-year review of neonatal sepsis and comparison with the previous fifty-year experience. Pediatr Infect Dis J 1990;9:819-25.

9. Grauel EL, Halle E, Bollmann R, Buchholz P, Buttenberg S. Neonatal septicemia: incidence, etiology, and outcome: a 6-year analysis. Acta Paediatr Scand Suppl 1989;360:113-9.

10. Tessin I, Trollfors B, Thiringer K. Incidence and aetiology of neonatal septicemia and meningitis in western Sweden, 1975-1986. Acta Paediatr Scand. 1990;79:1023-30.

11. Khair KB, Rahman MA, Sultana T, Roy CK, Rahman MQ, Ahmed AN. Role of hematologic scoring system in early diagnosis of neonatal septicemia. BSMMU J 2010;3:62-7.

12. Rodwell RL, Leslie AL, Tudehope DI. Early diagnosis of neonatal sepsis using a hematologic scoring system. Pubmed [abstract]. 1988. Didapat dari: http://www.ncbi. nlm.nih.gov/pubmed/3361389.

13. Narasimha A, Kumar HML. Significance of hematological scoring system (HSS) in early diagnosis of neonatal sepsis. Indian J Hematol Blood Transfus 2011;27:14-7.

14. Jumah DS, Hassan MK. Predictors of mortality outcome in neonatal sepsis MJBU 2007;25:11-8.

15. Seymour DG, Green M, Vaz FG. Making better decisions: construction of clinical scoring systems by the Spiegelhalter-Knill-Jones approach. Br Med J 1990;300:223-6.

16. Makkar M, Gupta C, Pathak R, Garg S, Mahajan NC. Performance evaluation of hematologic scoring system in early diagnosis of neonatal sepsis. J Clin Neonatol 2013;2:25-9.

17. Shirazi H, Riaz S, Tahir R. Role of the hematological profile in early diagnosis of neonatal sepsis. Ann. Pak Inst Med Sci 2010;6:152-5.

18. Dorling JS, Field DJ, Manktelow B. Neonatal disease severity scoring system. Arch Dis Child Fetal Neonatal Ed 2005;90:F11-6.

19. Richardson DK, Corcoran JD, Escobar GJ, Lee SK. SNAP-II and SNAPPE-II: simplified newborn illness severity and mortality risk scores. J Pediatr 2001; 138: 92-100.

20. Sundaram V, Dutta S, Ahluwalia J, Narang A. Score for neonatal acute physiology II predicts mortality and persistent organ dysfunction in neonates with severe septicemia. Indian Pediatrics 2009:46:775-80.

21. Waseem R, Shah AA, Khan MQ, Qureshi AW. Indicators of early outcome in neonatal sepsis. Biomedica 2005;21:117-2.

22. Kuppula VS, Meinzen-Derr J, Morrow AL, Schibler KR. Prolonged initial empirical antibiotic treatment is associated with adverse outcomes in premature infants. J Pediatr 2011;159:720-5.

23. Cantey JB, S_Anchez PJ. Prolonged Antibiotic Therapy for "Culture-Negative" Sepsis in Preterm Infants: It's Time to Stop!. J Jpeds 2011;7:707-708. 